\title{
e-Leadership: A Bibliometric Analysis
}

\author{
https://doi.org/10.3991/ijac.v13i1.12341 \\ Ingrid Garcia \\ Pablo Olavide University, Seville, Spain \\ ivgarcarealu.upo.es
}

\begin{abstract}
- e-leadership has been studied, during the late 1990s, with the rapid rise in advanced information technology (AIT) tools such as the internet, e-mail, video conferencing, WhatsApp, virtual teams, and virtual learning platforms. This research covers a deep review of the literature between 1990-2019 and the source data are derived from the Web of Science (WoS). In order to reveal the holistic landscape of this field, VOSviewer as popular visualization tools are employed to process the bibliographic data. We use VOSviewer. The most related terms in this field were obtained by co-occurrence analysis from abstracts and keywords. The terms and its clusters were illustrated on graphs and density maps were utilized. Also, findings show that the literature refers explicitly to e-leadership. There are a number of interesting insights to be found in the theoretical articles. The paper concludes with recommendations for further multidisciplinary research at the intersection of the fields of companies, educational technology and educational management, focusing on values, strategy, organization and leadership interactions, teaching and learning at all levels.
\end{abstract}

Keywords - Change management, e-leadership, technology integration, eteams, cluster, quantify bibliometrically, Web of Science (WoS) database, VOSviewer

\section{1 e-Leadership and Virtual Teams as Challenge}

\subsection{Leadership as challenge}

This study defines the relatively new leadership paradigm — e-leadership - that has arisen in little more than a decade. The literature on e-leadership settings is still young, e-leadership can be considered as a new phenomenon of leadership theory [1]; [2]. [3] calls it as an emergent leadership, past leadership research has not focused on issues confronting the leadership in organizations where work is mediated by Advanced Information Technology [AIT]. The term of e-leadership was used for this review and it was conceptualized based on the contributions of several authors; such as [4] and [8]. Accordingly, [4] e-leadership is defined as a "social influence process mediated by Advanced Information Technology (AIT) to produce a change in feelings, thinking, behavior, and/or performance with individuals, groups, and/or organizations." 
As first summarized in [5], literature review researchers agree on the fact that the virtual settings affect the traditional roles of leaders in face-to-face situations. Eleaders have to develop this in consideration when working with their teams. Also, [5] express the importance of how technology impacts leadership style, team motivation and performance. Some reasons to study emerging e-leadership are the revolution in communications that has continued to intensify as new technologies, complex technologies from birth is of enormous impact to leaders. One effect of the communication revolution has been the proliferation of new communication tools from which to choose, the ease of communication, and the challenge of communication overload and the "constant contact" [5].

According to the ideas mentioned above, e-leadership refers to resources associated with change of organizational patterns facilitated by the digital revolution. The rise of teams, telework, and emergent leadership patterns relies heavily on expedited electronic communication which e-leaders must master, manage and coordinate. This definition applies to ICT-field mediated methods to how new management forms are expected to transform or generate changes in different educational processes or "collaboration tools". There are two fundamental components of e-leadership: communication and technology; access to computer-mediated communication has become increasingly convenient and affordable.

[6] examine recent theoretical and empirical developments in the leadership literature, beginning with topics that are currently receiving attention in terms of research, theory, and practice. [6] begin by examining authentic leadership and its development, followed by work that takes a cognitive science approach. Also, they examine new-genre leadership theories, complexity leadership, and leadership that is shared, collective, or distributed. It has been important to examine the role of relationships through our review of leader-member exchange and the emerging work on followership.

[7] interpret that today's organizational leader grapples with two interrelated forces: The increasingly global dispersion of divisions and subunits, customers, stakeholders, and suppliers of the organization; and the exponential explosion in communication technology that has led to greater frequency of daily interactions with colleagues, coworkers, subordinates and bosses dispersed geographically. [7] postulate that in view of the rapid technology growth in organizations and their increasingly global reach, in the near future, e-leadership will be the routine rather than the exception in our thinking about what constitutes organizational leadership.

[8] proposes that, as part of a natural evolution of educational technology research, considerably more attention needs to be focused on research and development in eleadership. Building on selected prior literature, an updated framework of principles for effective e-leadership of educational technology is proposed, with specific reference to higher education, selected insights derived from e-leadership literature and on the author's experience of 30 years of professional practice, scholarship and research into educational technologies and leadership in education. [9] explain the development of a new fifth age of educational technology research in which it is argued that more critical, selective, strategic e-leadership approaches to the adoption and use of 
educational technology need to be progressed through research, development and training as the field matures.

\subsection{Importance of e-Team}

To bring clarity to this debate, the construct of e-team has been introduced to describe a new profile of e-leaders who constantly interact with technology. [4] created one of the first definitions of e-leader and the way of working leadership in virtual teams. The term e-team was conceptualized based on the contributions of several authors; such as [3], [4] and [5]. They agree that the introduction of digital tools affects the design of work, and, particularly, how people work together. Digitalization opens up new possibilities such as e-teams and smart working, introduces new communication tools, increases speed and information access, influences power structures, and increases efficiency and standardization.

The literature has tended to treat virtual teams as a single "ideal" type, yet there are several dimensions or characteristics that vary among and distinguish different types of virtual teams. It is significant to notice that getting a group of people to work together (physically) is not enough to make this group of people into a "team". Teams are different from working groups [3]. Virtual teams are defined as "interdependent groups of individuals that work across time, space, and organizational boundaries with communication links that are heavily dependent upon advanced information technologies" [6].

Also, open education of the 21 st century is quite closely connected with the development of electronic technologies, virtual teams have been increasingly used by organizations and educational institutions as a result of the development of technologies and globalization. [7] explore the challenges of creating and maintaining trust in a global virtual team whose members transcend time, space, and culture. The results suggest that global virtual teams may experience a form of "swift" trust, but such trust appears to be very fragile and temporal. The study raises a number of issues to be explored and debated by future research. Pragmatically, the study describes communication behaviors that might facilitate trust in global virtual teams.

[7] investigated the effects of transformational and transactional leadership styles and communication media on team interaction styles and outcomes. Teams communicated through one of the following three ways: face-to-face, desktop videoconference, or text-based chat.

[8] proposes avenues for future research, including methodological and theoretical considerations that are important to advancing our understanding of virtual teams.

[9] express that as the nature of work in today's organizations becomes more complex, dynamic, and global, there has been an increasing emphasis on far-flung, distributed, virtual teams as organizing units of work. Despite their growing prevalence, relatively little is known about this new form of work unit, we focus on delineating the dimensions of a typology to characterize different types of virtual teams. Propositions addressing leadership implications for the effective management of virtual teams are proposed and discussed [10]. 


\section{Methodology}

Bibliometric is the use of statistical methods to analyse books, articles, and other publications. Bibliometric mapping is a powerful tool for studying the structure and the dynamics of scientific fields [11, 12]. About studies on bibliometric mapping, there are some studies which have drawn attention on developing a software for bibliometric mapping like VOSviewer [13]. Also, we found that technical information on VOSviewer and on the VOS mapping and clustering techniques is provided in the following publications:

[14] Visualizing bibliometric networks; [15] Text mining and visualization using VOSviewer; [16] A unified approach to mapping and clustering of bibliometric networks; [17] How do health behavior interventions take account of social context? A literature trend and co-citation analysis; and [25] Distribution features and intellectual structures of digital humanities.

In these papers, we built co-authorship and co-occurrence keywords used in the scientific articles on e-leadership in order to establish possible trends and aims of the research. In fact, the data for this study was extracted from the WoS (October 12, 2019) and all the information was exported to the VOSviewer software. [20] was employed to generate the collaboration and word co-occurrence network. Also, VOSviewer can be used to construct networks of scientific publications, scientific journals, researchers, research organizations, countries, keywords, or terms. Items in these networks can be connected by co-authorship, co-occurrence, citation, bibliographic coupling, or co-citation links, also to construct a network, data from the WoS files can be used.

\section{$2.1 \quad$ Objectives}

The present article has two objectives: the first one is to quantify bibliometrically on the WoS database CLARIVATE, the scientific production on e-leadership in the shape of scientific articles and secondly, we construct with VOSviewer software networks of scientific publications, scientific journals, researchers, research organizations, countries, keywords, or terms, during the period ranging from January 1990 to October 2019.

\subsection{Method}

This research is characterized for being a systematic review of the literature, taking into account the principles established context for bibliometric studies through the use of the descriptive, quantitative and the application of semantic techniques, the analysis of social networks for the study of keywords, through their graphical and visual representation with the VOSviewer 1.6.12 software ${ }^{1}$.

\footnotetext{
${ }^{1}$ VOSviewer is a software tool for constructing and visualizing bibliometric networks. These networks may for instance include journals, researchers, or individual publications, and they can be constructed based on citation, bibliographic coupling, co-citation, or co-authorship relations. VOSviewer also offers
} 
The software selected for visualization is VOSviewer, a freely available computer program for bibliometric mapping. It pays special attention to the graphical representation of scientific maps. In addition, it is especially useful for constructing and displaying large scientific maps in an easy-to-understand way [18]. In particular, VOSviewer employs the visualization of similarities mapping technique and the main advantage of the software is the high quality of its visual representation [19]. We construct a network, data from WoS files, for searching the articles in the databases, the following equations were used: «e-leadership» OR «e-leader» OR «emergent leadership». Thus, at first 643 resources in the WoS, which were reduced to 347 (eleadership), after the application of the exclusion criteria and posterior manual elimination. VOSviewer provides three visualizations, referred to as the network visualization, the overlay visualization, and the density visualization.

The variables selected have been: main authors; abstract; title; keywords; research areas; number of articles published on e-leadership; number of citations received; journals with a higher index of citations; language; institutional affiliations; productivity according to year and country.

We picked up the bibliographic data with cited references for these 347 articles and exported them into WoS software for bibliometric analysis we presented for eleadership and analysis from 1990 to 2019 through the analysis from the WoS through the extraction of a txt file in the case of WoS named savedrecst.txt, and the posterior visual representation with the VOSviewer software 1.6.12. Additionally, the research focused on the use of science mapping to graphically map the data. As we said before, specifically, the study used the visualization of similarities (VOS) viewer software, using bibliometric maps, to show the structure and networks of authors, journals, etc.

In the first step we analyzed statistical analysis from the WoS data base. The second step was a bibliometric analysis.

\section{$3 \quad$ Results and Discuss}

\subsection{Statistical analysis}

Publications of e-leadership research: Yearly research output from the period of 1990 to 2019, the year-wise distribution of documents indexed in the WoS database is shown in Figure 1. In 1998, only one paper on e-leadership research was published, the number of publications was zero in the period of 1994-1995; and in 2012, the number of publications increased to 24 . This figure clearly shows that the growth rate of publication in the period of 1996-2002 was slow, but since 2007, the output of documents has been growing rapidly. This forward movement indicates that the research on e-leadership was consistently the focus of academics during the past decade, particularly in $2016-2017$.

text mining functionality that can be used to construct and visualize co-occurrence networks of important terms extracted from a body of scientific literature [20]. 


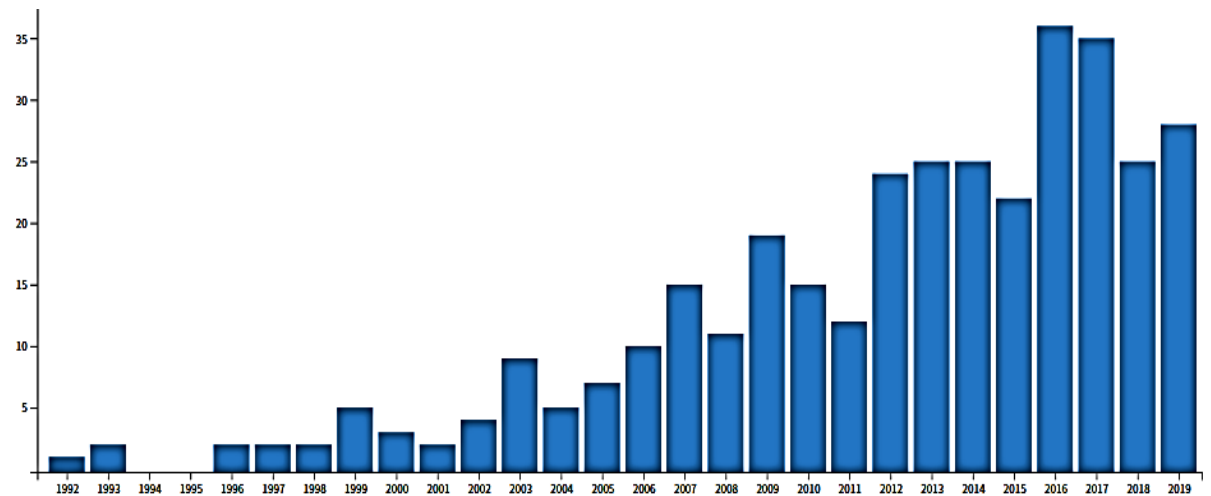

Fig. 1. Yearly publications of e-leadership research output from 1990 to 2019. Source WoS (2019).

Publishing languages: According to the statistical results from the WoS database, the scientific literature published on e-leadership for the whole period had been written in four languages. The distribution of language usage is shown in Figure 2. As expected, English is the dominant language, according to data gathered from the WoS database. Among the four languages, 330 articles (95.95 percent) are published in English, followed by eight articles ( 2.3 percent) in Spanish, six articles (1.15 percent) in French and three articles ( 0.598 percent) in German. One of the reasons for the use of English might be that English is widely used in the world, functioning as an international language. Also, some academic journals published in non-English countries or regions were not indexed in the WoS database.

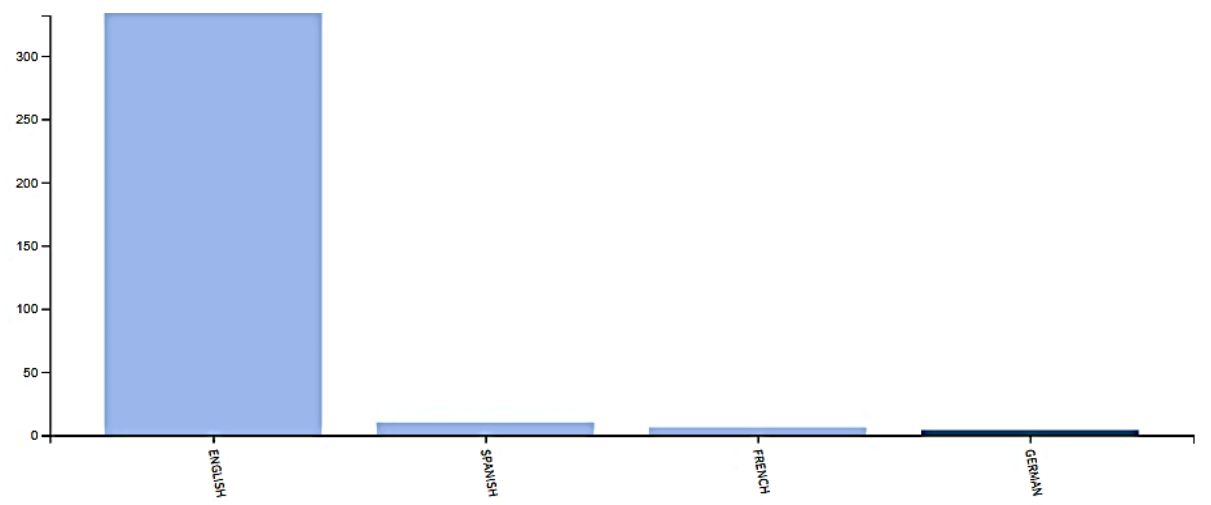

Fig. 2. Distribution of language use in e-leadership publications output from 1990 to 2019. Source WoS (2019).

Productive institutions: In relations of productive institutions, there are 476 different institutions worldwide showing research interest in e-leadership. In order to categorize the active and leading institutions in e-leadership investigation, the WoS database analyzes institution-based distribution of output to understand the produc- 
tivity level of institutions around the world. Table 1 and Figure 3 show the distribution of the top 10 most productive institutions ranked by the total number of publications and country.

Of the top 10 institutions, six are in the USA, two in the Netherlands, one in the UK, one in Canada, and one in Germany. As shown in Table 1, a university from the USA (University of Central Florida) ranks as the top one, followed by Erasmus University from the Netherlands, and the third position is Maastricht University from the Netherlands, followed by three universities from the USA (University of Maryland, University of Michigan and California State University, San Bernardino).

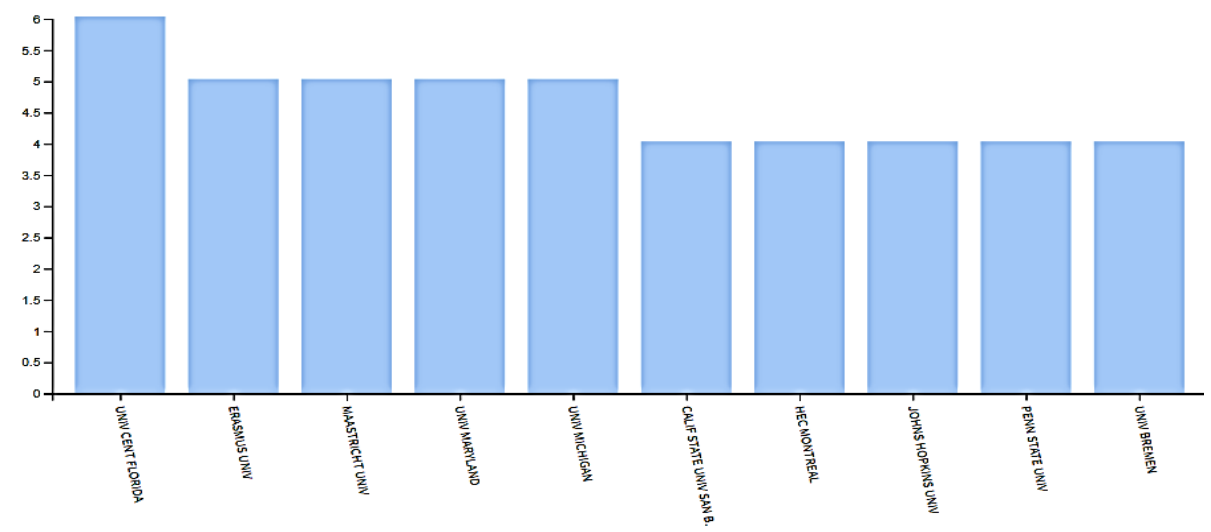

Fig. 3. Distribution of Institutions research in e-leadership output from 1990 to 2019. Source WoS (2019).

Table 1. The 10 most productive institutions ranked by country.

\begin{tabular}{|c|l|l|}
\hline Rank & \multicolumn{1}{|c|}{ University } & \multicolumn{1}{c|}{ Country } \\
\hline 1 & University of Central Florida & USA \\
\hline 2 & Erasmus University & Netherlands \\
\hline 3 & Maastricht University & Netherlands \\
\hline 4 & University of Maryland & USA \\
\hline 5 & University of Michigan & USA \\
\hline 6 & California State University San Bernardino & USA \\
\hline 7 & HEC Montreal & Canada \\
\hline 8 & Johns Hopkins University & USA \\
\hline 9 & Penn State University & USA \\
\hline 10 & University of Bremen & Germany \\
\hline
\end{tabular}

Source WoS (2019).

As we can see, it shows the dominance of English-speaking countries. It also indicates that higher education institutions are important innovation systems and play an active role in promoting the sustainable development of e-leadership research.

Analyze by category: According to all data and journal subject classification rules of the WoS database, each paper published by that journal is assigned to one category. Figure 4 shows the categories involved in the field of e-leadership. According to the results, over 25 subject categories were related to this research field. 
The most common category is management, which is the biggest one with a frequency of 108 , followed by education educational research (52), psychology applied (52), business (39) and computer science (36). The results indicate that the study of eleadership is an interdisciplinary subject. As we can see, Figure 5 shows: business, communication, computer science information systems, computer science interdisciplinary applications, computer science theory methods, development studies, economics, education educational research, engineering electrical electronic, engineering industrial, information science library science, management, nursing, psychology applied, psychology multidisciplinary, public administration, social sciences interdisciplinary.

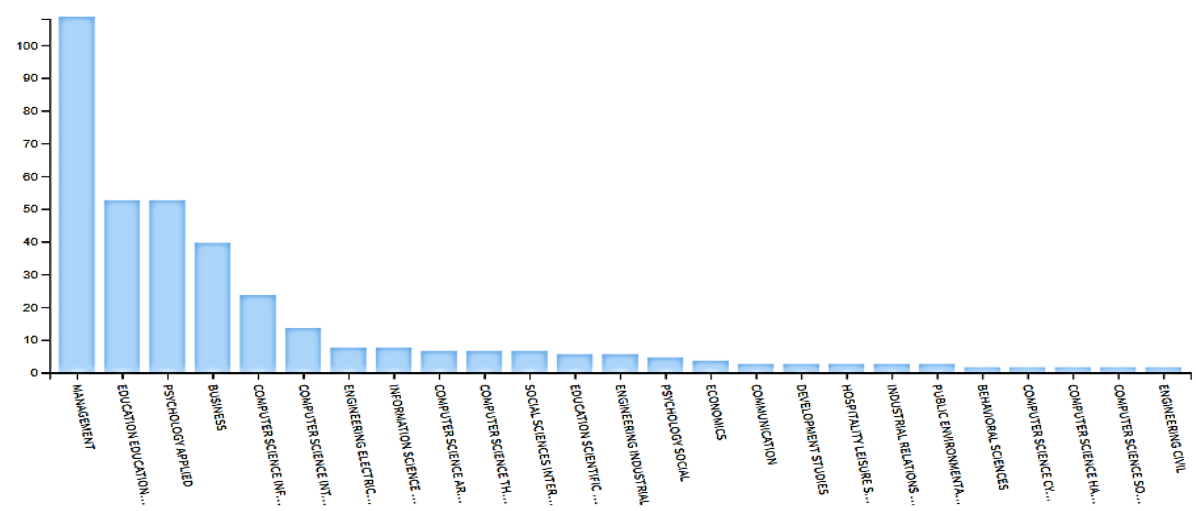

Fig. 4. Distribution of fields research in e-leadership output from 1990 to 2019. Source WoS (2019).

According to all data and journal subject classification rules of the WoS database, each paper published by that journal is assigned to one category. Figure 4 shows the categories involved in the field of e-leadership. According to the results, over 25 subject categories were related to this research field.

The most common category is management, which is the biggest one with a frequency of 108 , followed by education educational research (52), psychology applied (52), business (39) and computer science (36). The results indicate that the study of eleadership is an interdisciplinary subject. As we can see, Figure 5 shows: business, communication, computer science information systems, computer science interdisciplinary applications, computer science theory methods, development studies, economics, education educational research, engineering electrical electronic, engineering industrial, information science library science, management, nursing, psychology applied, psychology multidisciplinary, public administration, social sciences interdisciplinary.

Productive countries of the research: We analyzed and explored the WoS, specifically its Principal Collection, divided by Correct contents connect; Derwent, Korean Journal, Russian science and Scielo Citation. The principal 23 countries where the study of e-leadership stands out are represented in Figure 5 and are specific: USA, England, Spain, China. Australia, Finland, Latin America and South Korea. 


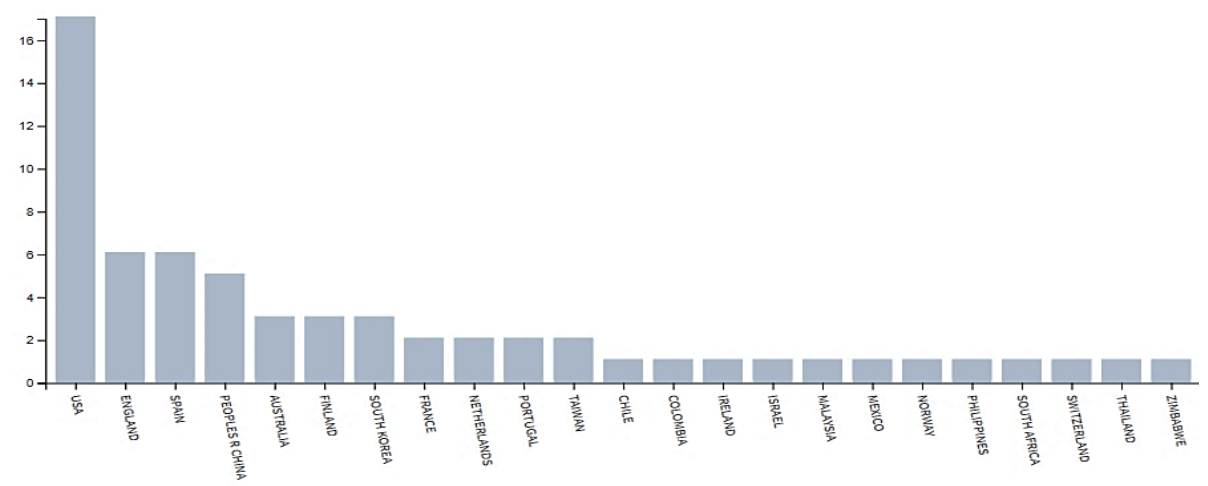

Fig. 5. Distribution of productive countries output from 1990 to 2019. Source WoS (2019).

\subsection{Bibliometric Analysis}

Author co-citation network: The network of e-leadership can be identified and interpreted by author co-citation analysis network which focuses on interrelationships among individual authors. This method offers a functional tool for representing a landscape of author co-citation networks, and plots the author co-citation network, which is composed of 347 of the most cited contributors and 131 links, in which the size of each node corresponds to the weight of citations of the author it represents. The links reflect a cooperative relationship between two authors. According to the number of co-citation frequency, the most highly cited authors and relevant information can be extracted from the author co-citation network. The study outlines the bibliometric indicators of the scientific research related to e-leadership during the research time frame from 1990 to 2019.

The analysis of co-authorship can help us understand the e-leadership network of different authors all over the world. The e-leadership network of the most productive authors generated, as shown in Figure 6 and Table 2, indicates the top cited articles in the e-leadership field. A color bar (CB) is shown in the bottom right corner of the visualization, colors are determined by years of items. The $\mathrm{CB}$ indicates how dates are mapped to colors and the production every five years. 


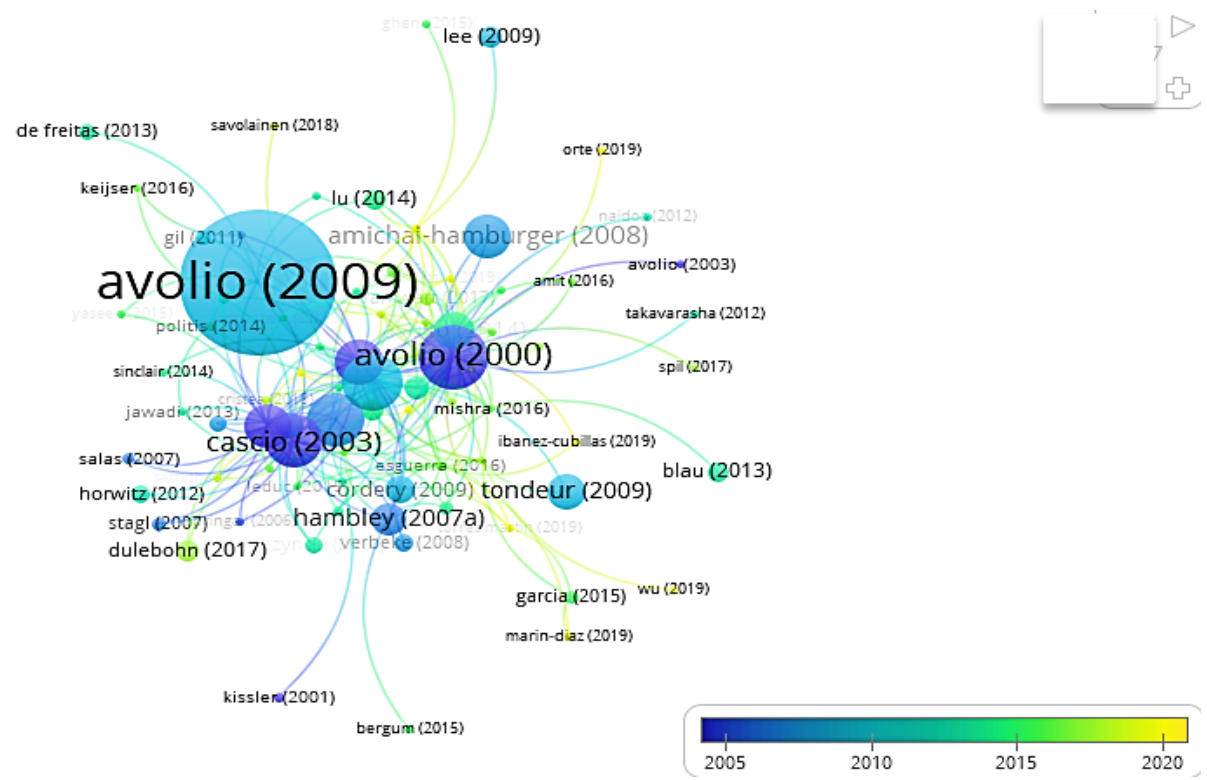

Fig. 6. Overlay visualization and co-authorship of e-leadership analysis from 1990-2019.

Term keywords co-occurrence network and mapping of terms: In our analysis, we use the techniques for constructing maps of keywords co-occurrence network. Bibliometric maps are especially useful when one has to deal with a relatively large body of literature and when one's interest is not only in the individual elements (keywords) that can be identified in this body of literature but also, in the way in which the various elements are interrelated.

In many cases, the full text of a document is not available, and only words in the title and sometimes also, in the abstract of a document are considered. An alternative is to use the keywords co-occurrence assigned to a document, in this part, delineation of the domain can be done by identifying relevant documents based on keywords in which a document was published. VOSviewer can for example be used to construct maps of keywords based on co-occurrence data. To expose and demonstrate the hot research topics better, the top 21 keywords are selected as core terms. VOSviewer, a clusters view of keywords co-occurrence network is generated in this manner, as Figure 7 shows. The co-occurrence network presents descriptors related to the topic of e-leadership, while also providing link-based information on their relationship. Of the 21 keywords selected, that of the largest centrality (the most frequently used keyword) was "e-leadership" Figure 7. 
Table 2. Top cited authors and articles in the e-leadership field.

\begin{tabular}{|c|c|c|c|c|c|}
\hline Author & Ref & Year & Title & Journal name & Cited \\
\hline $\begin{array}{l}\text { Avolio, B; Kahai, S; } \\
\text { Dodge,G. }\end{array}$ & {$[4]$} & 2000 & $\begin{array}{l}\text { E-leadership: Implica- } \\
\text { tions for theory, re- } \\
\text { search, and practice. }\end{array}$ & $\begin{array}{l}\text { Leadership } \\
\text { Quarterly }\end{array}$ & 228 \\
\hline Purvanova, R.; Bono, J. & [1] & 2009 & $\begin{array}{l}\text { Transformational lead- } \\
\text { ership in context: Face- } \\
\text { to-face and virtual } \\
\text { teams. }\end{array}$ & $\begin{array}{l}\text { Leadership } \\
\text { Quarterly }\end{array}$ & 122 \\
\hline $\begin{array}{l}\text { Cascio, W; Shurygailo, } \\
\text { S. }\end{array}$ & {$[21]$} & 2003 & $\begin{array}{l}\text { E-leadership and virtual } \\
\text { teams. }\end{array}$ & $\begin{array}{l}\text { Organizational } \\
\text { Dynamics }\end{array}$ & 107 \\
\hline $\begin{array}{l}\text { Hambley, L; O'Neill, T; } \\
\text { Kline, T. }\end{array}$ & {$[6]$} & 2007 & $\begin{array}{l}\text { Virtual team leadership: } \\
\text { The effects of leader- } \\
\text { ship style and commu- } \\
\text { nication medium on } \\
\text { team interaction styles } \\
\text { and outcomes. }\end{array}$ & $\begin{array}{l}\text { Organizational } \\
\text { Behavior \& } \\
\text { Human Decision } \\
\text { Processes }\end{array}$ & 106 \\
\hline Avolio, B; Kahai, S (5) & {$[5]$} & 2003 & $\begin{array}{l}\text { Adding the "E" to E- } \\
\text { leadership: How it may } \\
\text { impact your leadership. }\end{array}$ & $\begin{array}{l}\text { Organizational } \\
\text { Dynamics }\end{array}$ & 75 \\
\hline Zaccaro, S; Bader, P. & {$[22]$} & 2003 & $\begin{array}{l}\text { E-leadership and the } \\
\text { challenges of leading E- } \\
\text { teams: Minimizing the } \\
\text { bad and maximizing the } \\
\text { good. }\end{array}$ & $\begin{array}{l}\text { Organizational } \\
\text { Dynamics }\end{array}$ & 70 \\
\hline $\begin{array}{l}\text { Avolio, B; Sosik, J.; } \\
\text { Kahai, Surinder S.; et } \\
\text { ál.. }\end{array}$ & {$[23]$} & 2014 & $\begin{array}{l}\text { E-leadership: Re- } \\
\text { examining transfor- } \\
\text { mations in leadership } \\
\text { source and transmission. }\end{array}$ & $\begin{array}{l}\text { Leadership } \\
\text { Quarterly }\end{array}$ & 53 \\
\hline Jill, J. & [8] & 2013 & $\begin{array}{l}\text { e-Leadership in higher } \\
\text { education: The fifth } \\
\text { "age" of educational } \\
\text { technology research }\end{array}$ & $\begin{array}{l}\text { British Journal of } \\
\text { Educational } \\
\text { Technology }\end{array}$ & 21 \\
\hline Blau, I \& Presser, O. & {$[24]$} & 2013 & $\begin{array}{l}\text { e-Leadership of school } \\
\text { principals: Increasing } \\
\text { school effectiveness by } \\
\text { a school data manage- } \\
\text { ment system }\end{array}$ & $\begin{array}{l}\text { British Journal of } \\
\text { Educational } \\
\text { Technology }\end{array}$ & 15 \\
\hline
\end{tabular}

Source WoS (2019).

As Figure 7 and Figure 8 show, the terms with high co-occurrence frequencies between the period 1990-2019, are distinguished in three colored frames. The red frames contain terms related to "e-leadership", "virtual team" and "affect", while the green frames contain terms related to "role" and "leadership style", and the yellow frames contain terms related to "research" and "higher education".

To reveal and illustrate the hot research topics better, the top 31 keywords are selected as core terms with reference to the central idea of "e-leadership". By running VOSviewer, 13 clusters view of keywords co-occurrence network are generated in this manner, as Figure 7 and Figure 8 show. The keyword co-occurrence network presents descriptors related to the topic of e-leadership, while also providing linkbased information on their relationship. Of the 31 keywords selected, that of the largest centrality (the most frequently used keyword) was "e-leadership". 


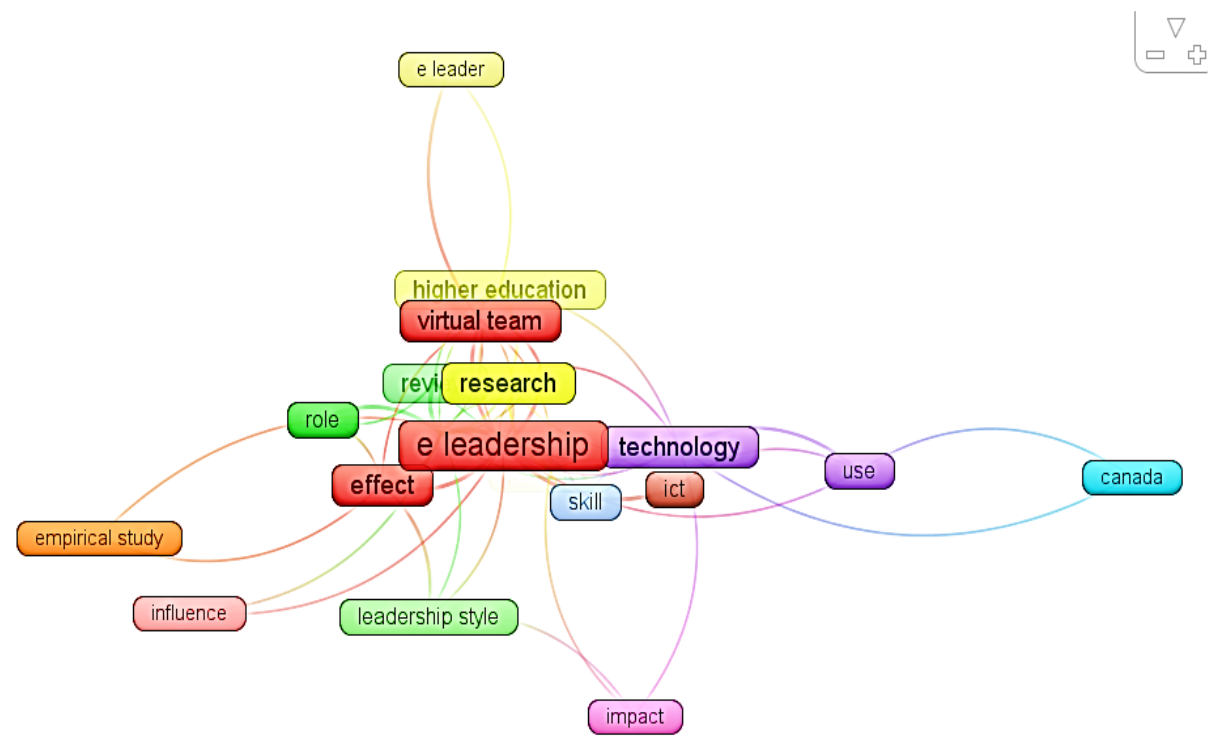

Fig. 7. Frames representation of keywords co-occurrence of e-leadership analysis from 19902019.

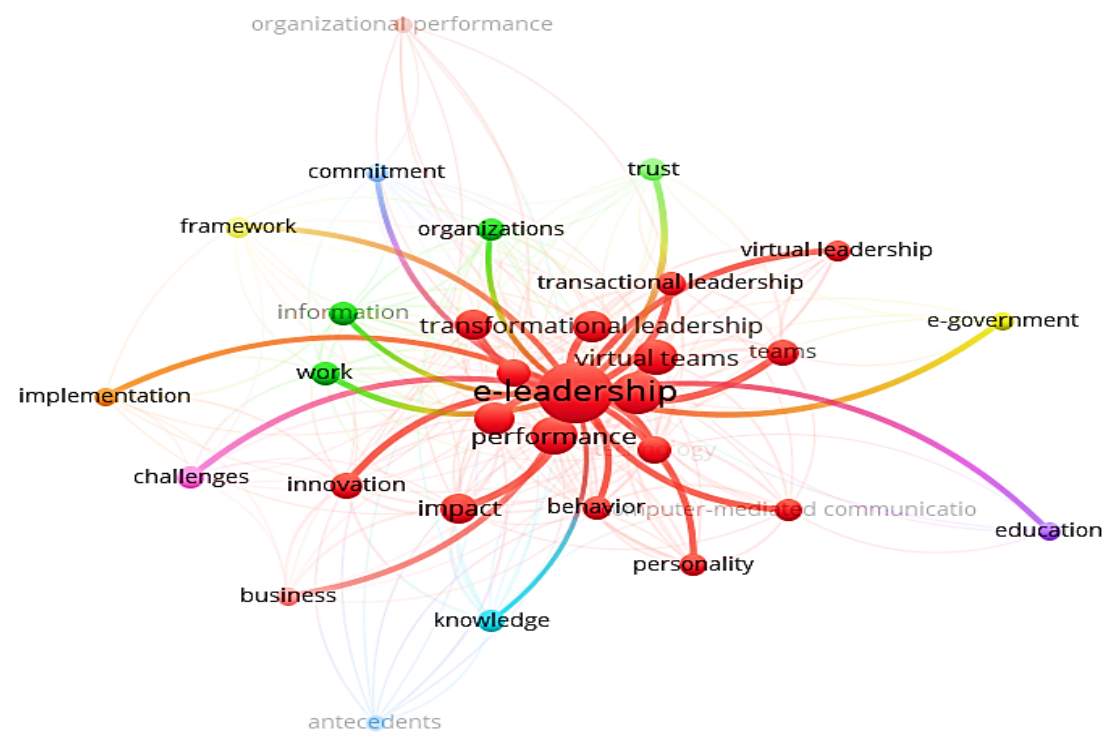

Fig. 8. Circles representation of keywords co-occurrence of e-leadership analysis from 19902019. 
Density map of e-leadership cluster: The concept density maps are based on the notion of concept density at a specific location in a concept map depends both on the number of neighboring concepts and on the importance of these concepts. A higher number of neighboring concepts and the smaller the distance between these concepts and the location under. Concept of density maps has been introduced by [12]. Consider the clusters density map. As Figure 9 shows there are 21 items divided by five clusters. The clusters can be defining as we show in Table 5, it shows the clusters' names, definitions and high most repeated terms of every cluster.

Considering the density map Figure 9, as it is seen from the left side (namely the cluster of e-leadership) the terms "performance" and "virtual team" can be seen at the center of the red field and can be accepted as the most important terms of the middle side. It can be said that these terms are the most important terms in the field.

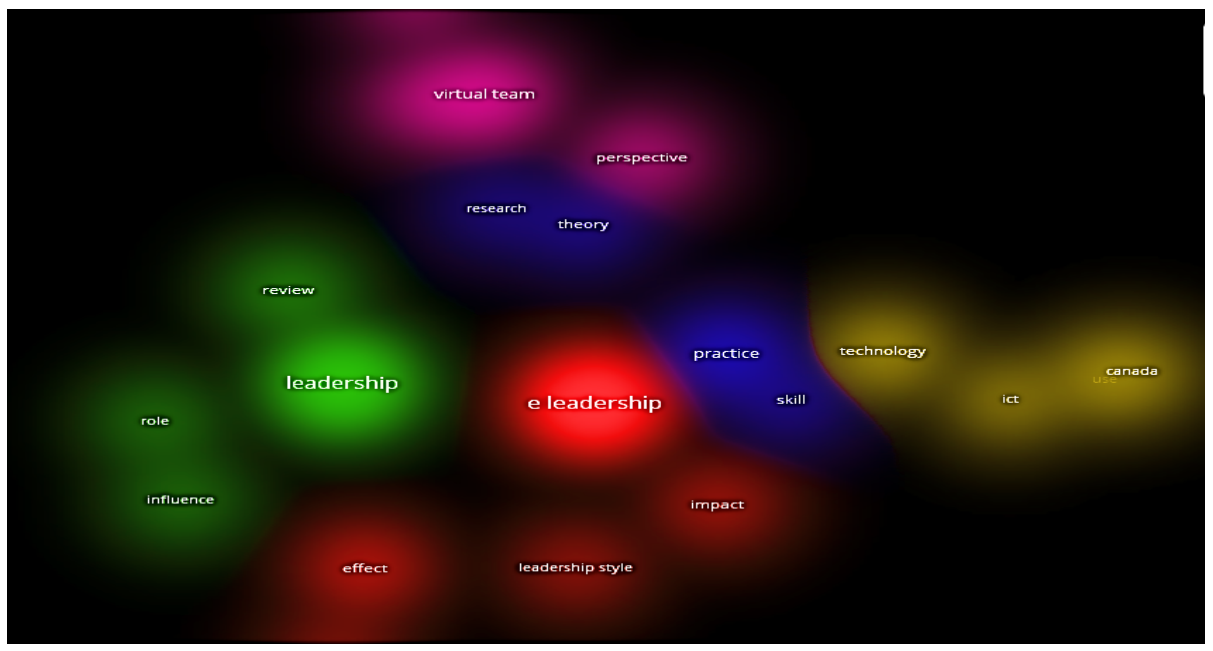

\begin{tabular}{|lll|}
\hline \multicolumn{1}{|c|}{ Cluster 1 } & \multicolumn{1}{c|}{ Cluster 3 } & \multicolumn{1}{c|}{ Cluster 5 } \\
\hline e-leadership & Influence & e-leader \\
effect & Leadership & Higher education \\
empirical study & Review & Perspective \\
impact & Role & Virtual team \\
leadership style & & \\
\hline \multicolumn{1}{|c|}{ Cluster 2 } & \multicolumn{1}{l}{ Cluster 4 } \\
\hline Practice & & \\
Research & Canada & \\
Skill & ICT & \\
Theory & Technology & \\
\hline
\end{tabular}

Fig. 9. Density map of e-leadership cluster from 1990-2019.

The most effective terms in the e-leadership field were illustrated in Figure 9. Red and blue fields of the map indicate the most important terms, important terms and less 
important terms in the field, respectively. It also shows the interrelationships of the terms with the other terms. The density view immediately reveals the general structure of the map. Especially for e-leadership, performance areas turn out to be important. These areas are very dense, which indicates that overall the journals in these areas receive a lot of citations. Considering the density map, as it is seen from the left side (namely the five clusters of e-leadership) the terms "e-leadership", effect", "empirical", "study", "impact", "leadership" and "style" can be seen at the center of the red field and can be accepted as the most important terms of the left side. On the right side of the map (namely the cluster 2 of e-leadership), the terms "practice", "research", "skill" and "theory" stand out.

\section{Conclusion}

The study presents a bibliometric overview of the leading trends that have occurred in the journals between 1990-2019, using the WoS database to collect bibliographic information and determine various bibliometric indicators. This work also presents a collaboration and a few co-occurrence networks to visualize the performance of the resources journal from a different perspective.

In this investigation, we analyzed 347 publications in the e-leadership field from different viewpoints by combining bibliometric with network methods. The publishing tendency of publications, countries, languages, journals, keywords and the authors were analyzed based on bibliometric analysis. These articles had explored the nature and extent of the representation of e-leadership disciplines and concepts relating to digital context in published literature.

Up to the authors' best knowledge, this is one of the few ever bibliometric studies to report related research in emergent leadership as e-leadership field. Our study provides some novel insights useful for researchers interested in advancing an evidencebased social media and e-leadership research and international research.

Finally, our study showed that bibliometric analysis is one of the best methodological tools to map published literature in a particular subject and to pinpoint research gaps in that subject.

\section{$5 \quad$ References}

[1] Purvanova, R. \& Bono, J. Transformational leadership in context: Face-to-face and virtual teams. The Leadership Quarterly, 20 (4), 343-357, 2009. https://doi.org/10.101 6/j.leaqua.2009.03.004

[2] Savolainen, T. Trust Building in e-Leadership - Important Skill for Technology-Mediated Management in the 21 st Century. International Conference on Management, Leadership \& Governance: 288-XI. Kidmore End: Academic Conferences International Limited, 2013.

[3] Garcia, I. Emergent leadership: is e-leadership importance in the quality of virtual education? RIED. Revista Iberoamericana de Educación a Distancia, 18 (1), 25-44, 2015. https://doi.org/10.5944/ried.18.1.13798 
[4] Avolio, B., Kahai, S. \& Dodge, G.: E-leadership: implications for theory, research, and practice. Leadership Q. 11(4), 615-668, 2000. https://doi.org/10.1016/s10489843(00)00062-X

[5] Avolio, B. \& Kahai, S. Adding the "E" to E-Leadership: How it May Impact Your Leadership. Organizational Dynamics, 31(4), 325-338, 2003. https://doi.org/10.1016/s00902616(02)00133-X

[6] Avolio, Bruce J.; Walumbwa, Fred O.; Weber, Todd J. Leadership: Current Theories, Research, and Future Directions. Annual Review of Psychology Collection: Annual Review $\begin{array}{llll}\text { of Psychology } 60 & \text { (1), 421-449. 2009. } \text { https://doi.org/10.1146/annur }\end{array}$ ev.psych.60.110707.163621

[7] Hambley, L., O’Neill, T., \& Kline, T. Virtual team leadership: The effects of leadership style and communication medium on team interaction styles and outcomes. Organizational behavior and human decision processes, 103(1), 1-20, 2007. https://doi.org/10.10 16/j.obhdp.2006.09.004

[8] Jill, J. e-Leadership in higher education: The fifth "age" of educational technology research. British Journal of Educational Technology, 44(6), 889-915. 2013. https://doi.org/10.1111/bjet.12103

[9] Bell, B. S., \& Kozlowski, S. W. A typology of virtual teams: Implications for effective leadership. Group \& Organization Management, 27(1), 14-49, 2002. https://doi.org/10.1177/1059601102027001003

[10] Mitzi M. Montoya-Weiss, Anne P. Massey \& Michael Song. Getting It Together: Temporal Coordination and Conflict Management in Global Virtual Teams. The Academy of Management Journal, 44 (6), 1251-1262, 2013. https://doi.org/10.2307/3069399

[11] Noyons, E. Science maps within a science policy context. In: H. F. Moed, W. Glanzel, and U. Schmoch (eds.) Handbook of quantitative science and technology research. Dordrecht: Kluwer Academic Publishers, 2004, pp. 237-255. https://doi.org/10.1007/1-4020-2755911

[12] Van Eck N., Waltman L., Noyons E., \& Buter R. Automatic term identification for bibliometric mapping. Scientometrics, 82(3):581-596, 2010. https://doi.org/10.1007/s11192-010$\underline{0173-0}$

[13] Van Eck, N. \& Waltman, L. Software survey: VOSviewer, a computer program for bibliometric mapping, Scientometrics, 84 (2), 523-538, 2010. https://doi.org/10.1007/s11192$\underline{009-0146-3}$

[14] Van Eck, N., \& Waltman, L. Visualizing bibliometric networks. In Y. Ding, R. Rousseau, \& D. Wolfram (Eds.), Measuring scholarly impact: Methods and practice (pp. 285-320). Springer.2014. https://doi.org/10.1007/978-3-319-10377-8 13

[15] Van Eck, N., \& Waltman, L. (2011). Text mining and visualization using VOSviewer. ISSI Newsletter, 7(3), 50-54, 2011.

[16] Waltman, L., Van Eck, N., \& Noyons, E. A unified approach to mapping and clustering of bibliometric networks. Journal of Informetrics, 4(4), 629-635. 2010. https://doi.org/10.10 16/j.joi.2010.07.002

[17] Holman, D., Lynch, R., \& Reeves, A. How do health behaviour interventions take account of social context? A literature trend and co-citation analysis. Health, 22(4), 389-410, 2018. https://doi.org/10.1177/1363459317695630

[18] Van Eck N., \& Waltman L. Software survey: VOSviewer, a computer program for bibliometric mapping. Scientometrics 84(2):523-543, 2010. https://doi.org/10.1007/s11192-009$\underline{0146-3}$ 
[19] Sinkovics, N. Enhancing the foundations for theorising through bibliometric mapping. International Marketing Review, 33 (3), 327-350, 2016. https://doi.org/10.1108/imr-10$\underline{2014-0341}$

[20] Van Eck, N., \& Waltman, L. VOSviewer Manual. Manual for VOSviewer version 1.6. 6 [Internet]. Leiden: Leiden University; 2017.

[21] Cascio, W., \& Shurygailo, S. E-leadership and virtual teams. Organizational Dynamics 31 (4) 362-376. 2616. https://doi.org/10.1016/s0090-2616(02)00130-4

[22] Zaccaro, S., \& Bader, P. E-leadership and the challenges of leading e-teams: Minimizing the bad and maximizing the good. Organizational Dynamics, 31(4), 377-377, 2003. https://doi.org/10.1016/s0090-2616(02)00129-8

[23] Avolio, B. J., Sosik, J. J., Kahai, S. S., \& Baker, B. (2014). E-leadership: Re-examining transformations in leadership source and transmission. Leadership Quarterly, 25(1), 105131. https://doi.org/10.1016/j.leaqua.2013.11.003

[24] Blau, I \& Presser, O. e-Leadership of school principals: Increasing school effectiveness by a school data management system. British Journal of Educational Technology, 44(6), 1000-1011, 2013. https://doi.org/10.1111/bjet.12088

[25] Wang, Q. Distribution features and intellectual structures of digital humanities. Journal of Documentation, 74(1), 223-246, 2018. https://doi.org/10.1108/jd-05-2017-0076

\section{Author}

Ingrid Garcia holds a Ph.D. in Social Science at Pablo Olavide University, Seville, Spain, graduated from the Catholic University Andrés Bello (UCAB) Bachelor of Accounting, Business Administration, Specialist and Master in Finance. She has extensive work experience, more than 15 years in executive positions in multinational Co and 12 years of university teaching experience in the Faculty of Economics. She has participated in several international congresses, writes articles, book chapters and symposiums. Emergent leadership as distributed leadership, e-leadership, organization management and, in particular, public school principals, are the main areas of her scientific research. She is working now on the distributed leadership, influenced by technology, the crushing processes of globalization, changes in laws and programs, innumerable conflicts social and curricula, uncontrolled immigration and inequalities.

Article submitted 2019-11-13. Resubmitted 2020-01-26. Final acceptance 2020-02-07. Final version published as submitted by the authors. 